\title{
Pulmonary Gunshot Wound Revealing Pulmonary Tuberculosis
}

Issoufou Ibrahim ${ }^{1 *}$, Lakranbi Marouane ${ }^{1}$, Sani Rabiou ${ }^{1}$, Belliraj Layla ${ }^{1}$, Ammor Fatmazahra ${ }^{1}$, Harmouchi Hicham $^{1}$, Sani Rachid ${ }^{2,3}$, Ouadnouni Yassine ${ }^{1,4}$, Smahi Mohamed ${ }^{1,4}$

${ }^{1}$ Department of Thoracic surgery, Teaching Hospital Hassan, Morocco

${ }^{2}$ Department of general surgery, HNN, Niger

${ }^{3}$ Faculty of health science, Abdou Moumouni University, Niger

${ }^{4}$ University Sidi Mohamed Ben Adellah, Morocco

Submission: December 21, 2016; Published: February 17, 2017

*Corresponding author: Issoufou Ibrahim, Department of Thoracic surgery, Teaching Hospital Hassan, Road Nador 1, Hay Amal Road Sefrou, 3000 Fez Sais Morocco, Tel: +212-6-97-12-55-26; Email alzoumib84@gmail.com

\section{Abstract}

Pulmonary tuberculosis is a major flail of mankind, $1 / 3$ of the world population is infected. In Morocco, the incidence is estimated by the Word Health Organization to 89 cases per 100000 inhabitants. However, gunshot assaults are rare. Many circumstances of discovery of tuberculosis were described. We present the case of an incidental finding of pulmonary tuberculosis in a young patient victim of a gun attack.

Keywords: Penetrating trauma; Hemothorax; Tuberculosis; Biopsy

Abbreviations: WHO: Word Health Organization; TB: Tuberculosis; ARDS: Acute Respiratory Distress Syndrome

\section{Introduction}

Pulmonary tuberculosis is a major health problem, infecting $1 / 3$ of the world population [1]. In Morocco, the incidence is estimated by WHO to 89 cases per 100000 inhabitants [2]
However, gunshot assaults are rare. Penetrating traumas are dominated by knives attack. It is following this epidemiological paradox that we present a case of pulmonary tuberculosis revealed by a pulmonary wound after a gunshot attack.

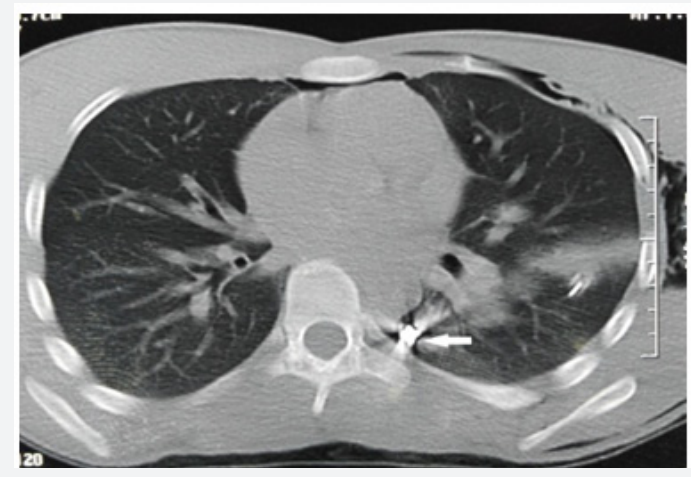

Figure $1 \mathrm{~A}$

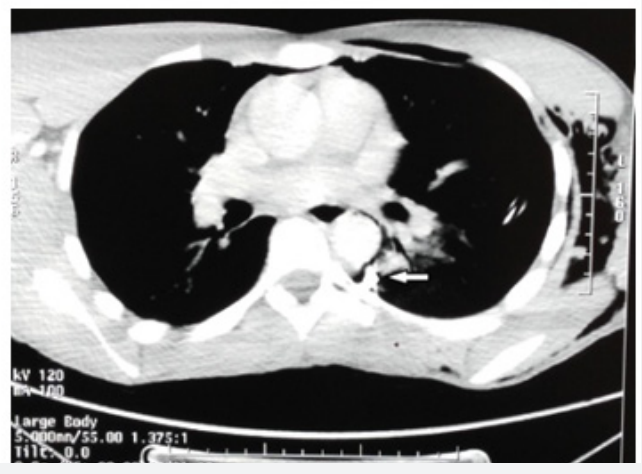

Figure 1B

Figure 1: Linear parenchymal condensation of the upper and lower left lobes representing the gunshot path (white arrow) separated from aorta by a tiny part of lung. 


\section{Case Presentation}

A young man of 23 years old without any past medical history, from a modest socioeconomic family was admitted to the emergency for left axillary gunshot wound that occurred 5 days before. On admission he had stable hemodynamic parameters. He presented severe dyspnea and left thoracic pain. Physical exam revealed an axillary wound inlet of $0.5 \mathrm{~cm}$, sub-cutaneous emphysema and air pleural effusion. There was no outlet. The left radial pulse was present and symmetric to the right. Chest X-ray showed a left abundant hemopneumothorax with the gunshot near aorta. An axillary chest tube was performed and $300 \mathrm{ml}$ of blood was evacuated. Chest CT angiography (Figure 1A \& 1B) showed linear parenchymal condensation of the upper and lower

left lobes representing the gunshot trajectory. This gunshot was separated from the aorta by a tiny part of lung. Neither hemomediastinum nor vascular injury was found. Surgery was retained for gunshot extraction. A conservative posterolateral thoracotomy showed blood clots and pachypleuritis. Also, the gunshot crossed the upper left lobe from top to bottom, penetrated the fissure on the side of lower lobe and fitted in the posterior part of the Fowler segment. Removal of the gunshot was performed after resecting a small collar of the lung. Other findings showed nodules on the basal part of left lower lobe which were biopsied. The postoperative course was uneventful. Histology of nodules showed caseo-follicular pulmonary tuberculosis. An antibacillary treatment was prescribed and the patient showed good clinical and radiological evolution (Figure 2).

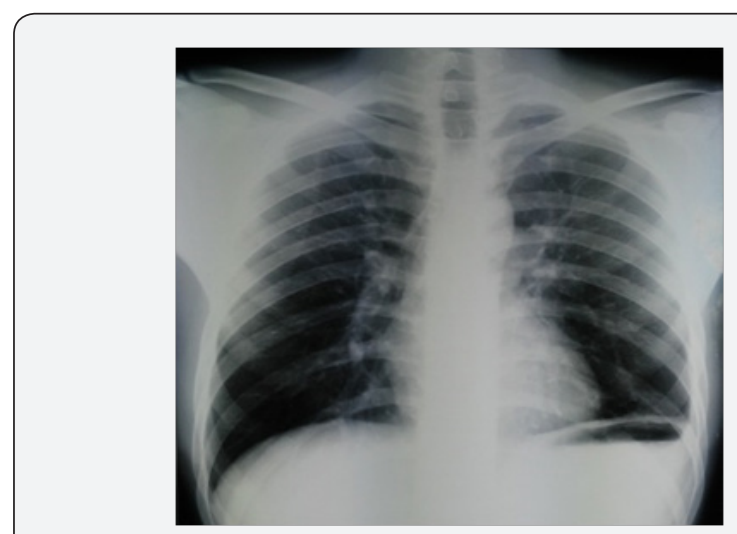

Figure 2: Follow up image after 2 months.

\section{Discussion}

Our observation is particular by the revealing mode of pulmonary tuberculosis. Indeed, it was discovered after a lung biopsy following incidental intra-operative suspicious lung nodules during gunshot extraction. To our knowledge this revealing mode has never been reported in literature. In France during 2008, $76 \%$ of tuberculosis patient were diagnosed following clinical signs, $3.9 \%$ following screening, $6.5 \%$ in the course of case investigation and $13.6 \%$ discovered incidentally after other investigations [3]. These findings are almost similar from ours in the Maghreb. Indeed, Ben Amar J et al showed in a Tunisian study that $73.8 \%$ of cases were diagnosed in community health care centers while $21 \%$ were discovered during screening [4]. We estimate that only $10 \%$ of persons who had contact with Koch bacilli will express the illness at one time of their life [1]. Therefore, asymptomatic forms are those usually discovered incidentally. In Maghreb and as in many other endemic countries, TB affects active young population causing significant socioeconomic impact. When it is asymptomatic, radiological signs may be absent or discrete especially in another clinical context such as hemothorax caused by gunshot pulmonary wound. Indeed, the limited criterion on chest radiography in the diagnosis of pulmonary tuberculosis has been showed in many studies as it can remain normal in over $15 \%$ of cases [5]. The CT scan which has better sensitivity remains so limited in paucibacillary tuberculosis. The combination of quantiferon dosage and CT scan would be an effective alternative with positive predictive value of $96 \%$ and negative predictive value of $92 \%$ [6]. Nevertheless, attention must be drawn to the importance of Mycobacterium tuberculosis culture and histological exam which remain the only way to confirm the diagnosis and to begin an antibacillary therapy [6]. In fact, the major risk is a reactivation of $\mathrm{TB}$ which will lead to active tuberculosis in case of immunodeficiency [7]. However, reduced immunity has been demonstrated in animals after pulmonary contusion, hemorrhagic shock and in cases of severe trauma [8]. This would imply an increased risk of TB reactivation in the pulmonary contusion by gunshot. Furthermore, as the major complications of pulmonary contusion is ARDS following superinfection [9], then one wonders if tuberculous pneumonia increases the risk of non-specific germs superinfection and therefore of ARDS. Hence the importance of lung biopsy called "de passage" that will confirm the diagnosis in this context of asymptomatic tuberculosis.

\section{Conclusion}

Pulmonary gunshot wound may be a circumstance of discovery of pulmonary tuberculosis clinically and radiologically asymptomatic. A lung biopsy called "de passage" should be performed for all suspicious lesions especially during a stressful surgery where the surgeon will tend to neglect this type of injury. Indeed histological confirmation of the asymptomatic forms is primordial to begin antibacillary treatment which is the only guarantee of a good prognosis in the context of tuberculous pneumonia and pulmonary contusion.

\section{References}

1. David JW, Peter AL, William AR (2011) Tuberculose pulmonaire. In: Greganti AM, et al. (Eds.), Médecine interne de Netter. Elsevier Masson, Paris, pp. 791-801.

2. Ministère de la santé marocain (2016) Situation Epidémiologique de la Tuberculose au Maroc - Année 2015. 
3. Che D, Antoine D (2011) Épidémiologie de la tuberculose en France en 2008. Med Mal Infect 41(7): 372-378.

4. Ben Amar J, Hassairi M, Ben Salah N, Charfi R, Tritar F, et al. (2015) Pulmonary tuberculosis: Diagnostic delay in Tunisia. Med Mal Infect 46(2): 79-86.

5. Fockyee C, Beigelman C, Daou S, Soussan M, Brauner M, et al. (2015) Imagerie de la tuberculose pulmonaire. Feuillets de radiologie 55(4) 206-230.

6. Hantous-Zannad S, Zidi A, Néji H, Attia M, Baccouche I, et al. (2015) Apport de l'imagerie dans la tuberculose thoracique. Rev Pneumol Clin 71-(2-3): 93-109.
7. Toujani S, Ben Salah N, Cherif J, Mjida M, Ouahchy Y, et al. (2015) La primo-infection et la tuberculose pulmonaire. Rev de Pneumol clin 71(2-3): 73-82.

8. Cerf C (2007) Contusions pulmonaires : aspects physiopathologiques et principes de prise en charge. Réanimation 16(1): 82-87.

9. Freysz M, Doussot C (2007) Traumatismes thoraciques fermés. EMC, Médecine d'urgence, Paris, 25-200.

Your next submission with Juniper Publishers will reach you the below assets

- Quality Editorial service

- Swift Peer Review

- Reprints availability

- E-prints Service

- Manuscript Podcast for convenient understanding

- Global attainment for your research

- Manuscript accessibility in different formats

( Pdf, E-pub, Full Text, Audio)

- Unceasing customer service

Track the below URL for one-step submission https://juniperpublishers.com/online-submission.php 